\title{
Materials Characterization of Plasma Deposited Copolymers using CFC-113, CFC-12 and PFC-116 with $\mathrm{C}_{2} \mathrm{H}_{4}$ Monomers
}

\author{
Osamu Tsuji, Takeshi Minaguchi, Kikuko Yoshimura, Hirohiko Nakano and Toshiaki Tatsuta
}

\author{
SAMCO INTERNATIONAL INC. \\ 36, Waraya-cho, Takeda, Fushimi-ku \\ Kyoto 612-8443 Japan
}

\begin{abstract}
CFC-113 $\left(\mathrm{Cl}_{2} \mathrm{FC} / \mathrm{CClF} 2\right), \mathrm{CFC}-12\left(\mathrm{CCl}_{2} \mathrm{~F}_{2}\right)$, and PFC-116 $\left(\mathrm{F}_{3} \mathrm{C}_{2} \mathrm{CF}_{3}\right)$ were each combined with ethylene $\left(\mathrm{H}_{2} \mathrm{C}=\mathrm{CH}_{2}\right)$ in plasma copolymerization to deposit polymer films. The relative deposition rate was shown to be CFC-113 > CFC-12 > PFC-116, which indicates that the presence of $\mathrm{Cl}$ may serve to accelerate the polymerization rate. With a $\mathrm{C}_{2} \mathrm{H}_{4}$ mixing ratio of 1:1, the $\mathrm{C}-\mathrm{H}$ (stretching vibration) peak of the IR spectrum from the resulting film disappeared for $\mathrm{CFC}-113 / \mathrm{CCl}_{4}$, which contains $\mathrm{Cl}$. In comparison, the $\mathrm{C}-\mathrm{H}$ peak for PFC-116, which does not contain $\mathrm{Cl}$, is still apparent, indicating that an $\mathrm{H}$ abstraction reaction took place. The results of thermal stability showed that a weight loss starts at $200^{\circ} \mathrm{C}$ for polymers deposited by CFC- 113 and CFC- 12 , and at $250^{\circ} \mathrm{C}$ for polymers deposited by PFC-116. The melting point exceeded $300^{\circ} \mathrm{C}$ for all polymers, and was in excess of $400^{\circ} \mathrm{C}$ for PFC-116. Dielectric constant of polymers deposited by PFC$116 / \mathrm{C}_{2} \mathrm{H}_{4}$, which contains $\mathrm{H}$, was stable at 2.9 regardless of the source gas mixing ratio. Polymers deposited with CFC-113 and CFC-12 demonstrated a decrease in dielectric constant $(1.9 \sim 2.1)$ as the CFCs concentration was increased. These results indicate that polymer films deposited in a plasma copolymerization using monomer gases including CFCs may potentially be used in various applications, such as materials for micro electronic devices.
\end{abstract}

Keywords : Chlorofluorocarbon, plasma copolymer, CFCs-ethylene mixed monomer,

low dielectric constant

\section{Introduction}

In recent years chlorofluorocarbons (CFCs) have been widely used as coolants and as cleaning agents. However, from the standpoint of environmental protection their use has been internationally prohibited, and currently work is underway to recover the remainder of the existing CFCs. At present, most CFCs processing is performed at the high temperature decomposition. However, we have found that using the plasma copolymerization method to deposit the CFCs as a solid polymer film offers the following benefits: (1) Low-energy requirements (several 100W), (2) Byproducts of the reaction are easy to handle, (3) Byproducts of the reaction are polymers that contain $\mathrm{Cl}$ and $\mathrm{F}$, and can be recycled by use in

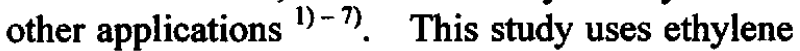
$\left(\mathrm{H}_{2} \mathrm{C}=\mathrm{CH}_{2}\right)$ as an additive source material to accelerate the copolymer deposition of $\mathrm{CFC}-113$ $\left(\mathrm{Cl}_{2} \mathrm{FC} / \mathrm{CClF}{ }_{2}\right), \mathrm{CFC}-12\left(\mathrm{CCl}_{2} \mathrm{~F}_{2}\right)$, and PFC-116 $\left(\mathrm{F}_{3} \mathrm{C} / \mathrm{CF}_{3}\right)$. We investigated the effects of monomer composition on the deposition reaction, chemical structure, physical properties and electrical properties of the CFCs copolymer films.

\section{Experimental}

\section{2-1. Plasma Reactor}

The plasma copolymerization reaction was carried out in a SAMCO PD-10 polymerization system, which is shown in Fig. 1. The stainless steel (SUS 304) bell-jar reaction chamber has a diameter of $160 \mathrm{~mm}$, and contains SUS 304 parallel plate electrodes. $13.56 \mathrm{MHz}$ radio frequency power is transmitted to the electrodes via a matching network. Prior to the deposition process, the substrate material is placed on the 


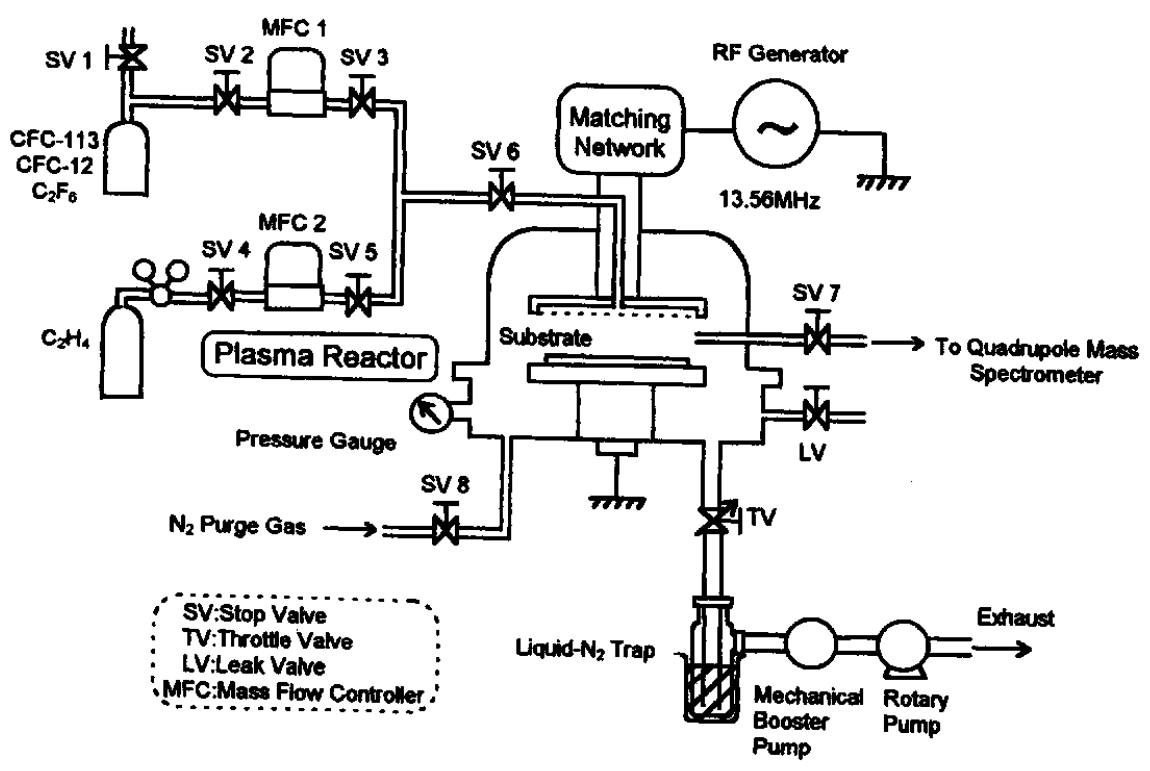

Fig.1. Schematic Diagram of the Plasma Reactor and an Associated Instrumentation.

lower electrode, and the reactor is evacuated with a mechanical booster pump $\left(100 \mathrm{~m}^{3} / \mathrm{hr}\right.$.) and a mechanical rotary pump $\left(0.3 \mathrm{~m}^{3} / \mathrm{min}\right.$.). Vacuum pressure within the reactor is measured with a thermocouple vacuum gauge. The CFC-12, PFC116 , and $\mathrm{C}_{2} \mathrm{H}_{4}$ gas monomers are stored in 10 liter gas cylinders, and the CFC-113 liquid monomer is stored in a metal container, which vaporizes the liquid under reduced pressure. The CFC gases, which are the main source materials for the experiment, and the $\mathrm{C}_{2} \mathrm{H}_{4}$, which is added to accelerate the reaction, are supplied to the reaction chamber via mass flow controlled gas lines. After mixing the CFCs gas with the $\mathrm{C}_{2} \mathrm{H}_{4}$, the mixture flows through the upper shower electrode and into the reactor. The reactor is also equipped to allow for the use of $\mathrm{O}_{2}$ and $\mathrm{N}_{2}$ gases, a cold trap, and a view port for the attachment of analytical equipment. This study was carried out with r.f. power of 100 watts, a reactor vacuum level of 0.3 or 0.4 torr, and a total gas flow rate of $40 \mathrm{sccm}$.

\section{2-2. Materials}

This study used CFC-113 manufactured by Mitsui Fluorochemicals Ltd., CFC-12 manufactured by Showa Denko, and $\mathrm{C}_{2} \mathrm{~F}_{6}$ manufactured by Sumitomo Seika Ltd. In terms of substrates, we used glass substrates for the thermal analysis of the films, and 4 inch-diameter silicon wafers (undoped, $\mathrm{n}^{+}$type doped) as required by the $I R$, XPS analysis and $C-V$ measurement.

\section{2-3. Measurement and Analysis}

The thickness of the polymer film deposited on the substrates was measured with an Ulvac Dektak 3030 film thickness measurement system, which detects the height of steps on the substrate. We used the film thickness data to calculate the film deposition rate. The IR absorption spectrum was measured using a Perkin-Elmer Model 1000 FT-IR spectrophotometer system. A Shimadzu ESCA-3200 X-ray photoelectron spectrometer was used to analyze the X-ray photoelectron spectrum. Thermal analysis was carried out with the Shimadzu DTG-50, which simultaneously performs differential thermal analysis and thermogravimetry. The rate of temperature was programmed to be $2.50^{\circ} \mathrm{C} /$ minute when measured with a nitrogen gas flow rate at $20 \mathrm{ml} /$ minute. The dielectric constant was measured using a Keithley model $590 \mathrm{C}-\mathrm{V}$ analyzer. We prepared the deposition substrates by cutting low-resistivity silicon wafers $\left(0.02-0.08 \Omega / \mathrm{cm}\right.$, Sb-doped, $\mathrm{n}^{+}$ type) into $2 \times 2 \mathrm{~cm}^{2}$ squares. Portions of the substrates were masked prior to deposition of 0.5 $\mu \mathrm{m}$ of copolymer film. We deposited gold film of $1 \mathrm{~mm}$ in diameter by $0.2 \mu \mathrm{m}$ thick via vacuum evaporation at nine locations on the copolymer film. In order to avoid contact with the film, we also deposited gold on the portions of the substrate uncoated with copolymer. We used a tungsten 
probe with a tip diameter of $25 \mu \mathrm{m}$ to measure the capacitance $(\mathrm{C})[\mathrm{pF}]$ up to the measured electrode. We determined the dielectric constant $(\varepsilon \mathrm{r})$ the following the formula to calculate from the capacitance data: $\varepsilon \mathrm{r}=\mathrm{C} \times \mathrm{d} / \varepsilon_{0} \times \mathrm{S}, \mathrm{d}=$ film thickness $(0.5 \mu \mathrm{m}), \varepsilon_{0}=$ dielectric constant of vacuum environment (8.854), $\mathrm{S}=$ area of electrode $\left(0.785 \mathrm{~mm}^{2}\right)$

It should be noted that the dielectric constant data obtained in this study produced almost identical measurements at of $100 \mathrm{kHz}$ and $1 \mathrm{MHz}$.

\section{Results and Discussion}

\section{3-1. Deposition Rate}

Deposition rate evaluation was carried out with each type of CFCs at various $\mathrm{C}_{2} \mathrm{H}_{4}$ mixing ratios. The results of deposition rates are summarized in Fig. 2. Relation of the elemental composition of the CFCs monomer, the deposition rate of the monomer combined with $\mathrm{C}_{2} \mathrm{H}_{4}$ was faster than the deposition rate of the CFC monomer alone. The maximum deposition rate for each $\mathrm{CFC}$ was reached at a mixing ratio of $\mathrm{CFC}: \mathrm{C}_{2} \mathrm{H}_{4}=1: 1$.

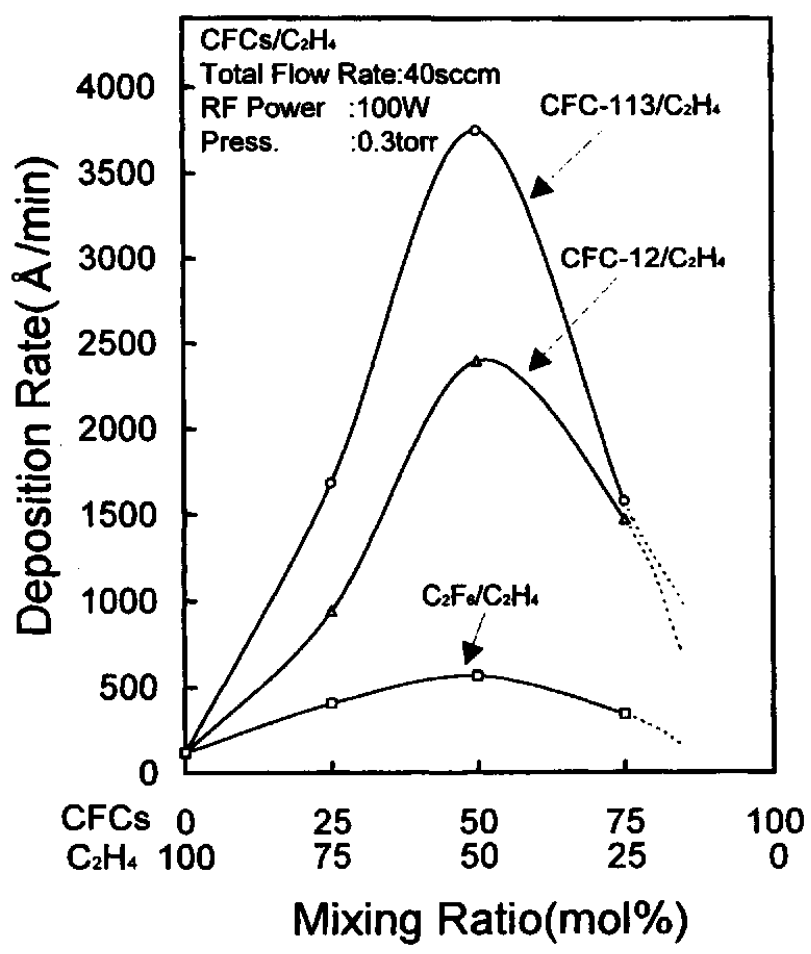

Fig.2.Deposition Rate of CFCs with $\mathrm{C}_{2} \mathrm{H}_{4}$ Gas Mixture.
However, it was demonstrated that when the same $\mathrm{CFC} / \mathrm{C}_{2} \mathrm{H}_{4}$ mixture ratio is used, the relationship between the deposition rates shows CFC-113 > CFC-12 > PFC-116. With the exception of the CFC-113 and CFC- 12 at $\mathrm{C}_{2} \mathrm{H}_{4}: 25 \%$ mixture ratios, there is a substantial difference in the deposition rates of the various CFCs. It is known that hydrocarbon monomers exhibit significant increases in plasma polymerization rates when even a small amount of a halogenated compound is added with the reaction. Therefore the above phenomenon can be explained as being caused by disassociated atomic halogens actively abstracting hydrogen atoms ${ }^{8), 9)}$. Despite the fact that the amount of carbon, which composed as the frame of the copolymers, is CFC-113: CFC- $12: \mathrm{C}_{2} \mathrm{~F}_{6}=2$ : $1: 2$, the deposition rate is in a sequence determined by the $\mathrm{Cl}$ content $(3: 2: 0)$, which indicates that the presence of $\mathrm{Cl}$ may greatly contribute to accelerate the polymerization rate.

When we observe the XPS spectrum of the copolymers and atomic ratio of $\mathrm{Cl} / \mathrm{C}$ and $\mathrm{F} / \mathrm{C}$, it can be noted that depending on the CFCs used and the monomer mixing ratio, there is significant variation in the amount of hologens contained in the copolymer. It may be deduced from this fact that even monomers with highly similar basic compositions may have different plasma reaction mechanisms.

\section{3-2. Infrared Spectrum}

We carried out the infrared spectrum analysis to determine the effect of differences in source monomers has on the molecular structure of the copolymers. In order to allow for a clear comparison of the results, we analyzed the copolymers from the ethane-structure monomers CFC-113 and PFC-116 and the methane-structure monomers $\mathrm{CCl}_{4}$ and $\mathrm{CF}_{4}$ at mixing ratios of CFCs : $\mathrm{C}_{2} \mathrm{H}_{4}=1: 1$. The results are shown in Fig. 3. Corresponding of $\mathrm{C}-\mathrm{H}$ strong absorption peaks in the stretching vibration of $2840-3000 \mathrm{~cm}^{-1}$. This C-H absorption is clearly evident in copolymers formed from monomers not containing $\mathrm{Cl}$, but it does not appear in copolymers formed from monomers containing $\mathrm{Cl}$. This results suggested that compared with $\mathrm{F}, \mathrm{Cl}$ has a significant effect in accelerating the dehydrogenation reaction. 

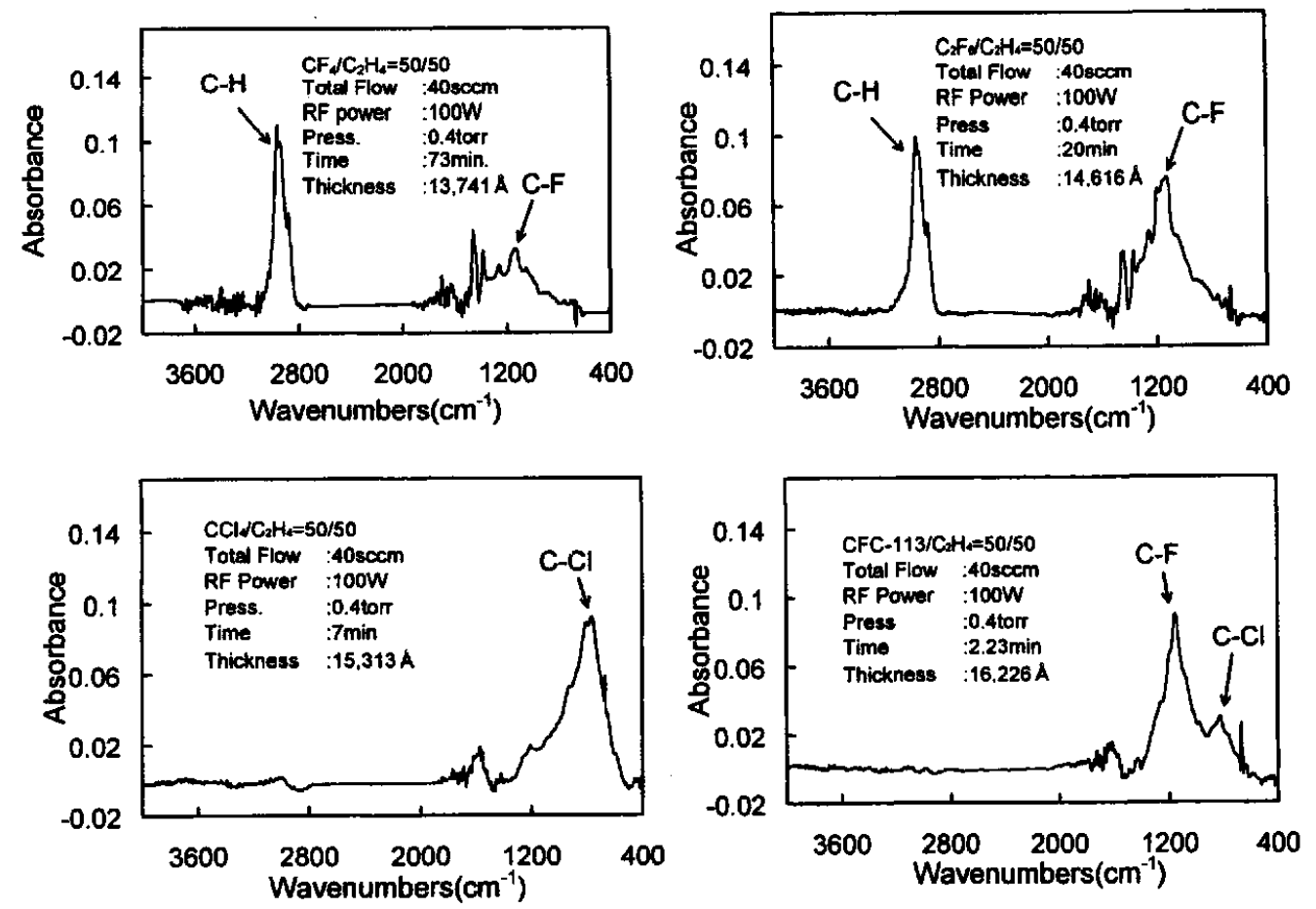

Fig.3.FTIR Spectrum of the CFCs/ $\mathrm{C}_{2} \mathrm{H}_{4}$ Copolymers.

As our above results, it may suggested that the increases in plasma polymerization rates that hydrocarbon monomers exhibit when halogenated compounds are added to the reaction is caused by disassociated atomic halogens abstracting hydrogen. This reaction mechanism hypothesis is supported by the results in Fig. 3. that shows the following copolymerization rates for CFCs mixed with $\mathrm{C}_{2} \mathrm{H}_{4}: \quad \mathrm{CF}_{4}: \mathrm{C}_{2} \mathrm{~F}_{6}: \mathrm{CCl}_{4}: \mathrm{CFC}-113=1: 4:$ $12: 39$. We concluded that $\mathrm{C}=\mathrm{H}$ shows strong absorption peaks in the stretching vibration at $1660-1600 \mathrm{~cm}^{-1}$. This peak is not observed copolymers when the copolymerization process, therefore we concluded that $\mathrm{C}=\mathrm{C}$ is incorporated polymers during the polymerization process.

\section{3-3. Thermogravimetry}

Fluorine containing polymers containing, particularly perfluoropolymers, usually have excellent thermal resistance properties ${ }^{10}$. In order to understand the thermal characteristics of the copolymers in this study, we obtained thermogravimetry. As shown in Fig 4., Cl containing polymers deposited with CFC-113 and CFC-12 begin to exhibit weight loss as the temperature exceeds $100^{\circ} \mathrm{C}$. Differential thermal analysis were performed simultaneously, and the results indicate that the samples were observed exothermic reaction. It can be inferred from this data that decomposition of the polymer had started. According to temperature increased, the rate of weight loss reached a peak, slowed down over a certain range, and then increased again. These changes took place respectively at approximately $240^{\circ} \mathrm{C}, 250^{\circ} \mathrm{C}$, and $560^{\circ} \mathrm{C}$ with $\mathrm{CFC}-113$, and $190^{\circ} \mathrm{C}, 350^{\circ} \mathrm{C}$, and $480^{\circ} \mathrm{C}$ with CFC- 12 . The second shift in the rate of weight loss coincides with an endothermic reaction peak with the differential thermal analysis data. This peak is suggested to be the melting completion point.

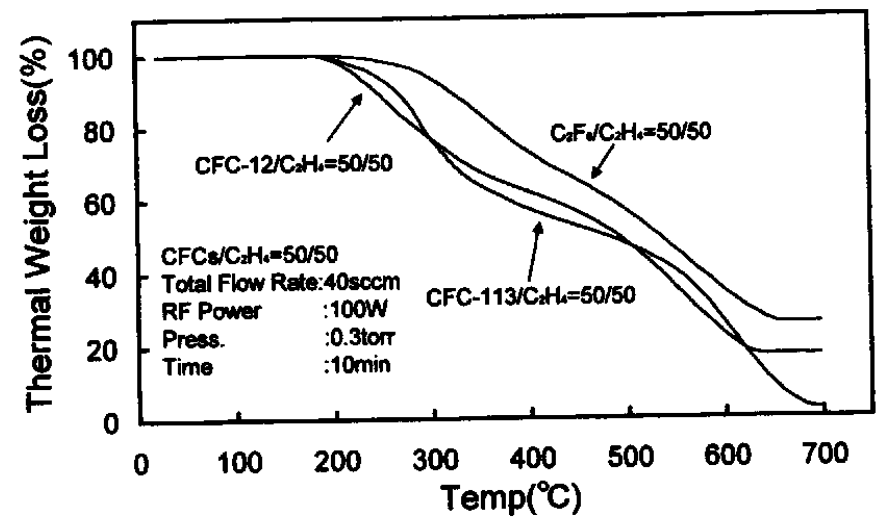

Fig.4.Thermal Stability of $\mathrm{CFCs} / \mathrm{C}_{2} \mathrm{H}_{4}$ Copolymer. 
In comparison, the copolymer film derived from PFC-116 does not demonstrate significant loss weight until reaching $250^{\circ} \mathrm{C}$. From $270^{\circ} \mathrm{C}$ to $550^{\circ} \mathrm{C}$, where there is an endothermic reaction peak, the rate of weight loss increases in an almost linear relationship. When compared with the $\mathrm{Cl}$ containing copolymers, the rate of weight loss is lower for the copolymer films derived from PFC116 at all temperature ranges. These results suggest that the copolymers not containing $\mathrm{Cl}$ exhibit superior thermal resistance properties. In addition, the cross-linking structures in plasma copolymers contribute to their thermal resistance properties being superior to those of conventional polymers. The melting point for $\left(\mathrm{CF}_{2} / \mathrm{CF}_{2}\right)_{\mathrm{n}}$, $\left(\mathrm{CClF} / \mathrm{CF}_{2}\right)_{\mathrm{n}}$, and $\left(\mathrm{CH}_{2} / \mathrm{CF}_{2}\right)_{\mathrm{n}}$ shown in related literature are respectively $327^{\circ} \mathrm{C}, 220^{\circ} \mathrm{C}$, and $156^{\circ} \mathrm{C}$. This data shows that while a molecular weight distribution can be widely observed, the melting points of the plasma copolymers is clearly higher.

\section{3-4. Dielectric Constant}

In recent years there has been much attention focused on the use of F-containing polymer films for use as organic dielectric films. Fig. 5. shows the dielectric constant of the plasma copolymers deposited in this study as measured at $100 \mathrm{kHz}$.

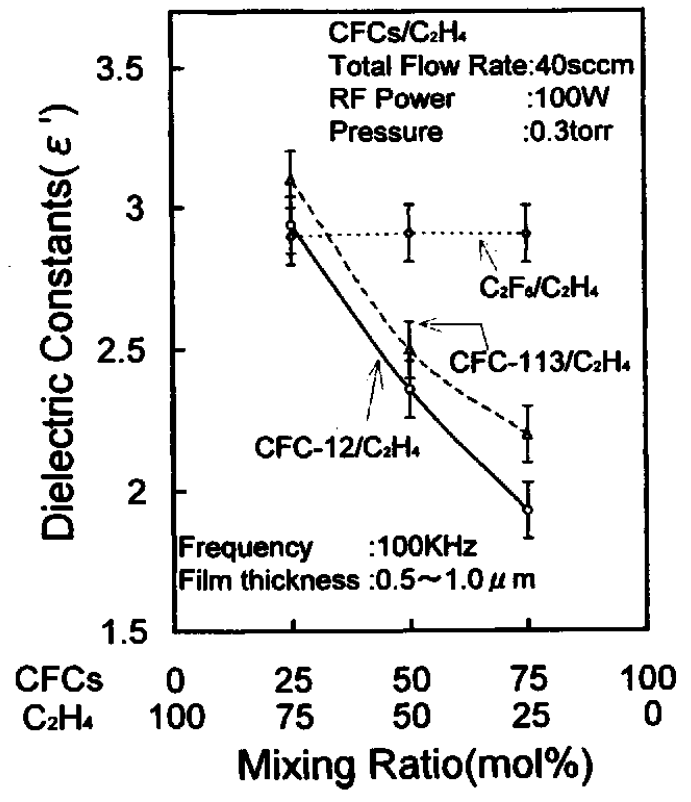

Fig.5.The Dielectric Constants of the CFCs/C $2 \mathrm{H}_{4}$ Copolymer Versus the Mol ratio of CFCs to $\mathrm{C}_{2} \mathrm{H}_{4}$ in the Feed Gas.
Copolymers formed from CFC-113/ $\mathrm{C}_{2} \mathrm{H}_{4}$ and CFC-12/ $\mathrm{C}_{2} \mathrm{H}_{4}$ exhibit a decrease in dielectric constant as the gas mixing ratio of CFCs increases. In comparison, the dielectric constant of polymers deposited by $\mathrm{PFC}-116 / \mathrm{C}_{2} \mathrm{H}_{4}$ is constant at 2.9 with various source gas mixing ratio. XPS spectrum data shows that the variation in elemental composition of copolymers formed from CFC-113 and CFC-12 at CFC mixture ratios of $50 \%$ and $75 \%$ is not significant. This indicates that the difference in dielectric constant may be caused by differences in the molecular structures of the copolymers, such as a variation in the degree of cross-linking structures. The fact that the copolymer deposited with PFC-116/ $\mathrm{C}_{2} \mathrm{H}_{4}$ monomers demonstrates a high dielectric constant is thought to be caused by the existence of hydrogen in the chemical structure. Hydrofluorocarbons containing both $\mathrm{H}$, which has a low electronegativity level, and $\mathrm{F}$, which has a high electronegativity level, have asymmetrical molecular structures that contain large electric dipole moment, which contribute to high dielectric constants. Based on elemental analysis, the amount of hydrogen contained in polymers deposited with CFC-113/ $\mathrm{C}_{2} \mathrm{H}_{4}$ at CFC-113 monomer mixing ratios of $25 \%, 50 \%$ and $75 \%$ is respectively $2.71 \%$, $0.87 \%$, and $0.24 \%$. As per the IR spectrum data, copolymers deposited with $\mathrm{PFC}-116 / \mathrm{C}_{2} \mathrm{H}_{4}$ contain much higher levels of hydrogen, which is thought to be the reason for the higher dielectric constant. The dielectric constants for $\left(\mathrm{CF}_{2} / \mathrm{CF}_{2}\right)_{\mathrm{n}}$ and $\left(\mathrm{CH}_{2} / \mathrm{CF}_{2}\right)_{\mathrm{n}}$ shown in related literature are respectively2.0 -2.2 when measured at $1 \mathrm{MHz}$. While these do not reach the levels demonstrated by perfluoropolymer, these films do have the required electrical characteristics to make them candidates for use as next generation interlayer dielectric films.

\section{Conclusion}

We established that it is possible to use CFCs of varied molecular structures as gas monomers to be mixed with ethylene for copolymerization and deposition as polymer films. All copolymers covered in this study exhibited high thermal resistance and low dielectric constants. However, the elemental composition and physical properties of the copolymers 
deposited varies depending on the chemical structure of the CFCs and the mixing ratio of the ethylene and CFCs monomers. These results indicate that it would be possible to deposit films for a variety of applications by selecting monomer materials and optimizing the copolymerization parameters and additives depending on the performance requirements of the application. This would not only contribute to environmental protection through the recovery of harmful CFCs, but would also allow for the proactive reuse of these materials as electronic materials.

\section{Acknowledgment}

The authors are acknowledge to the RITE (Research Institute of Innovative Technology for the Earth) for supporting this research project, and this experimental.

\section{References}

1. O. Tsuji, M. Sawai, H. Nakano and T. Minaguchi, $8^{\text {th }}$ Symp. On Plasma Sci. for Mater., Proc. (1995) 137.

2. O. Tsuji, M. Sawai, H. Nakano, T. Minaguchi, and T. Wydeven, $12^{\text {th }}$ Int. Symp. Plasma Chem., Minneapolis, Minn., Abstr. (1995) 983.
3. O. Tsuji, T. Minaguchi, H. Nakano and T. Tatsuta, $3^{\text {rd }}$ Asia-Pacific Conf. on Plasma Sci. \& Tech., Proc. (1996) 111.

4. O. Tsuji, T. Minaguchi, H. Nakano, M. Sawai and T. Tatsuta, Piping and Equipment, Vol. 9, (1996) 73.

5. O. Tsuji, M. Sawai, H. Nakano and T. Minaguchi, J. Photopolym. Sci. Tech., 8, (1995) 393.

6. O. Tsuji, T. Minaguchi, H. Nakano and T. Tatsuta, ibid., 10, (1997) 143.

7. O. Tsuji, T. Minaguchi, $H$. Nakano and T. Tatsuta, Jpn. J. Appl. Phys., 36, Pt. 1, No. 7B, (1997) 4964.

8. Y. Osada, T. Tsunoda, K. Nakajima, K. Honda, A. Mizumoto, M. Miyamura, S Morita, Plasma Polymerization, Tokyo Kagaku Dojin, Tokyo, (1986) 39.

9. Japan Science Advancement Society Plasma Materials \& Science $153^{\text {rd }}$ Committee, Plasma Materials \& Science Handbook, Ohm-sha Publishing, Tokyo, (1992) 570.

10. T. Satokawa, Functional Fluorine Macromolecules, Japan Industrial Newspaper Publishing Co., Tokyo, (1982) 4.

11. Chemistry Handbook, ed. Chem. Soc. Jpn., (1991) 528 . 